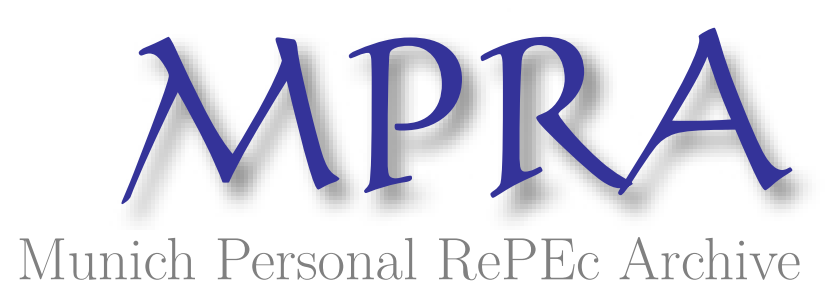

\title{
Economic Recession and Informal Sector Workers
}

Chaudhuri, Sarbajit
University of Calcutta

24 April 2009

Online at https://mpra.ub.uni-muenchen.de/18033/

MPRA Paper No. 18033, posted 22 Oct 2009 09:51 UTC 


\title{
Economic Recession and Informal Sector Workers
}

\author{
Sarbajit Chaudhuri \\ Professor \\ Dept. of Economics \\ University of Calcutta \\ 56A, B.T. Road \\ Kolkata 700050
}

India.

\begin{abstract}
Address for communication: Dr. Sarbajit Chaudhuri, 23 Dr. P.N. Guha Road, Belgharia, Kolkata 700083, India. Tel: 91-33-541-0455 (R), 91-33-557-5082 (C.U.) Fax: 91-33-2844-1490

(P) E-mail: sarbajitch@yahoo.com, sarbajitchaudhuri@yahoo.com
\end{abstract}

(This version: April 2009)

\begin{abstract}
The paper develops a three-sector specific factor model with Harris-Todaro type unemployment to examine the consequences of economic recession in the skilled sector on the informal sector workforce. It finds that while a decrease in the price of high-skill commodity raises both the informal (rural) sector wage and unemployment of unskilled labour, a drop in emigration of skilled labour produces exactly the opposite effects. The effects of these policies on the welfare of unskilled workers in terms of the welfare measure of Sen (1974) have also been studied. The paper recommends a protectionist policy to the unskilled labour-intensive sector for protecting the interest of the vulnerable section of the working population.
\end{abstract}

Keywords: Skilled labour; unskilled labour; economic recession; informal wage; urban unemployment

JEL classification: F13; J31. 


\section{Economic Recession and Informal Sector Workers}

\section{Introduction}

The financial and economic crisis that started in 2008 has deep implications for employment across the world. While the precise consequences cannot be predicted, it appears certain that both jobs and wage levels will suffer in many developing countries. The crisis is underscoring the relevance of the ILO's Decent Work Agenda. As per the annual Global Employment Trends report (2009) of the ILO the global economic crisis could result in an additional 18 million unemployed in the world and increased levels of vulnerable people in employment.

The economic crisis is bound to produce a significant impact on the informal sector which has emerged as an important institution in the entire developing world. It is beyond any doubt that the informal sector plays a very significant role in employment in developing countries constituting at least 70 per cent of total employment of the working population (Agenor 1996). In case of India this figure is over 90 per cent if one includes agriculture.

Labour market theory suggests an increase in informal activities as a result of economic turmoil, since informal employment can act as a buffer when people are laid off in the formal sector and need to find new job opportunities. Furthermore, an economy going into recession might experience a shift from the tradable to the non-tradable sectors, which again would strengthen informality. Empirical evidences from Latin American countries like Argentina and many Asian countries support the predicted shift towards more informal employment.

The economic crisis that originated in developed countries affects the developing economies in a number of ways. The fall in the imports of the developed nations from developing countries has spelt gloom. Consequent decline in commodity prices have resulted in lower export earnings, which left the latter countries high and dry. Developing countries which depend on primary and processed products are hit hard. Countries like India and China that are large exporters of highskill commodities like computer software are facing serious problem due to decreased demand 
from developed countries resulting in lower prices for these products. For India, it is even a bigger problem because India is the land of IT outsourcing and a lot of large western companies outsource their IT services to Indian companies. So, it is obvious that the supply of works for Indian outsourcing companies will suffer until the crisis gets over.

Falling demand, collapsing commodity prices and the international credit crunch are all impacting most heavily on the world's poorest countries and thus on hundreds of millions of people who are already poverty stricken. The ILO (2009) report also said that in this scenario some 200 million workers, mostly in developing economies, could be pushed into extreme poverty.

On the other hand, during economic downturns migrant workers in the developed nations are often the first to lose their jobs and while some may well choose to return home, policies aimed at sending migrant workers home tend to be based on the perception that "migrants take jobs" or "compete for welfare benefits". More restrictive immigration policies are adopted to protect the local labour market and in response to a demand for fewer foreign workers. For example, a reduction in the number of migrants to be admitted for employment has already been announced in some countries (Italy, U.K.) or is under discussion in others (e.g. U.S. and Australia). In Spain, the Government has introduced financial incentives to encourage unemployed migrants to return home. Such protectionist policies on the part of the rich nations accentuate the miseries of the developing economies.

Under the circumstances, the present paper is designed to examine the consequences of economic recession on the unskilled labour market in a developing economy. This is important because unskilled workers constitute the most vulnerable group of the working population. In particular the effects of a decline in the world price of a high-skill commodity and a fall in emigration of skilled labour will be examined on the informal wage, unemployment and welfare of unskilled workers. A three-sector Harris-Todaro (1970) (HT hereafter) type of model has been employed for the purpose of the analysis. While a decrease in the price of high-skill commodity raises both the informal (rural) sector wage and unemployment of unskilled labour, a drop in 
emigration of skilled labour produces exactly the opposite effects. In order to protect its vulnerable group of workers the country should fall back upon the protectionist policy and resort a price subsidy policy to the unskilled labour-intensive (informal) sector which is expected to produce an unequivocal improvement in welfare of the poor unskilled workers.

\section{The Model}

We consider a small open dual economy consisting of three sectors: rural, low-skill manufacturing and high-skill sectors. The last two are urban sectors. The rural sector (sector 1) produces an agricultural commodity by using unskilled labour, capital and land. The urban lowskill sector (sector 2) produces its output with the help of unskilled labour and capital. Finally, sector 3 produces a high-skill commodity by means of skilled labour and capital. So, land and skilled labour are specific to sectors 1 and 3, respectively while capital is perfectly mobile among all the three sectors of the economy. On the other hand, unskilled labour is imperfectly mobile between the rural and low-skill urban sectors. Sector 2 faces a unionized labour market where unskilled workers receive a contractual wage, $W^{*}$, while the unskilled wage rate in the rural sector, $W$, is market determined. The two wage rates are related by the Harris-Todaro (1970) condition of migration equilibrium where the expected urban wage equals the rural wage rate and $W^{*}>W$. Hence, there is urban unemployment of unskilled labour. Sectors 1 and 3 are the two export sectors while sector 2 is the import-competing sector. All the three commodity prices are given by the small open economy assumption. Sector 2 uses capital more intensively with respect to unskilled labour vis-à-vis sector 1. Production functions exhibit constant returns to scale with positive and diminishing marginal productivity to each factor. Finally, commodity 2 is chosen as the numeraire.

The following symbols will be used for formal presentation of the model.

$a_{K i}=$ amount of capital required to produce 1 unit of output in the $i$ th sector, $i=1,2,3$;

$a_{N i}=$ amount of land required to produce 1 unit of output in sector 1 ;

$a_{L i}=$ unskilled labour-output ratio in the $i$ th sector, $i=1,2$; 
$a_{S 3}=$ skilled labour-output ratio in sector 3;

$P_{i}=$ exogenously given relative price of the $i$ th commodity, $i=1,3$;

$X_{i}=$ level of output of the $i$ th sector, $i=1,2,3$;

$W_{S}=$ wage rate of skilled labour;

$W^{*}=$ unionized unskilled wage in sector 2;

$W=$ competitive wage rate of unskilled labour in sector 1 ;

$r=$ return to capital;

$R=$ return to land;

$L=$ endowment of unskilled labour;

$S=$ endowment of skilled labour;

$S_{0}=$ number of skilled workers migrating to developed countries;

$L_{U}=$ urban unemployment of unskilled labour;

$K=$ economy's aggregate capital stock;

$N=$ economy's land endowment;

$\theta_{j i}=$ distributive share of the $j$ th input in the $i$ th sector for $j=N, L, S, K$ and $i=1,2,3$;

$\lambda_{j i}=$ proportion of the $j$ th input employed in the $i$ th sector for $j=L, K$ and $i=1,2,3$;

' $\wedge$ '= proportional change.

Given the perfectly competitive commodity markets the three price-unit cost equality conditions relating to the three industries are as follows.

$$
\begin{aligned}
& W a_{L 1}+r a_{K 1}+R a_{N 1}=P_{1} \\
& W^{*} a_{L 2}+r a_{K 2}=1 \\
& W_{S} a_{S 3}+r a_{K 3}=P_{3}
\end{aligned}
$$

Full utilization of land, capital and skilled labour, respectively, imply

$$
\begin{aligned}
& a_{N 1} X_{1}=N \\
& a_{K 1} X_{1}+a_{K 2} X_{2}+a_{K 3} X_{3}=K
\end{aligned}
$$


$a_{S 3} X_{3}=S-S_{0}$

In the migration equilibrium there exists urban unemployment of unskilled labour. The unskilled labour endowment equation (after normalizing the endowment to unity) is given by

$$
a_{L 1} X_{1}+a_{L 2} X_{2}+L_{U}=1
$$

In an HT framework the unskilled labour allocation mechanism is such that in the labor market equilibrium, the rural wage rate, $W$, equals the expected wage income in the urban sector.

Since the probability of finding a job in the urban low-skill manufacturing sector is $\left(a_{L 2} X_{2} /\left(a_{L 2} X_{2}+L_{U}\right)\right)$ the expected unskilled wage in the manufacturing sector is $\left(W * a_{L 2} X_{2} /\left(a_{L 2} X_{2}+L_{U}\right)\right)$. Therefore, the rural-urban migration equilibrium condition for unskilled labour is expressed as $\left(W * a_{L 2} X_{2} /\left(a_{L 2} X_{2}+L_{U}\right)\right)=W$ or equivalently,

$$
\frac{W^{*}}{W} a_{L 2} X_{2}+a_{L 1} X_{1}=1
$$

Using (4) and (6) equations (5) and (8) can be rewritten as follows.

$$
\begin{aligned}
& \frac{a_{K 1} N}{a_{N 1}}+a_{K 2} X_{2}+\frac{a_{K 3}}{a_{S 3}}\left(S-S_{0}\right)=K \\
& \frac{W^{*}}{W} a_{L 2} X_{2}+\frac{a_{L 1} N}{a_{N 1}}=1
\end{aligned}
$$

\section{The general equilibrium analysis and comparative statics}

In this general equilibrium model there are eight endogenous variables: $W, W_{S}, r, R, X_{1}, X_{2}, X_{3}$ and $L_{U}$ and the same number of independent equations; namely, equations (1) - (4), (5.1), (6), (7) and (8.1). This is an indecomposable production structure. $r$ is obtained from (2) as $W^{*}$ is given. Plugging the value of $r$ into (3) $W_{S}$ is found. So $r$ and $W_{S}$ depend only on 
commodity prices but not on factor endowments. Then $W, R$ and $X_{2}$ are simultaneously solved from equations (1), (5.1) and (8.1).

As sectors 1 and 2 use two common inputs, unskilled labour and capital, these can be classified in terms of factor intensities. ${ }^{1}$ It is sensible to assume that sector 2 is more capital-intensive than sector 1 with respect to unskilled labour in value sense. This implies that $\left(a_{K 2} / W * a_{L 2}\right)>\left(a_{K 1} / W a_{L 1}\right)$.

\subsection{Effects of economic recession on informal wage and unemployment of unskilled labour}

In this section of the paper we are going to examine the consequences of economic recession in the skilled sector on the informal sector wage and urban unemployment of unskilled labour. An economic recession in the skilled labour market is captured in two ways. It leads to a decline in the price of the high-skill commodity, $P_{3}$, and a decrease in the emigration of skilled labour, $S_{0}$.

Differentiating equations (1), (5.1) and (8.1) we respectively obtain

$\theta_{L 1} \hat{W}+\theta_{N 1} \hat{R}=0$

$-B_{1} \hat{W}+B_{1} \hat{R}+\lambda_{K 2} \hat{X}_{2}=\left(B_{2} \hat{S}_{0}-B_{3} \hat{P}_{3}\right)$

$-B_{4} \hat{W}+B_{5} \hat{R}+\lambda_{L 2}^{*} \hat{X}_{2}=0$

where:

$$
\left.\begin{array}{l}
B_{1}=\lambda_{K 1} S_{N L}^{1}>0 ; B_{2}=\lambda_{K 3}\left(\frac{S_{0}}{S-S_{0}}\right)>0 ; B_{3}=\frac{\lambda_{K 3}\left(S_{K S}^{3}+S_{S K}^{3}\right)}{\theta_{S 3}}>0 ; \\
B_{4}=\left[\lambda_{L 1}\left(S_{L N}^{1}+S_{N L}^{1}\right)+\lambda_{L 2}^{*}\right]>0 B_{5}=\left[\lambda_{L 1}\left(S_{L N}^{1}+S_{N L}^{1}\right)\right]>0 ; \lambda_{L 2}^{*}=\frac{W^{*}}{W} \lambda_{L 2}>0 .
\end{array}\right\}
$$

Arranging equations (9) - (11) in a matrix notation we obtain

\footnotetext{
${ }^{1}$ Note that apart from unskilled labour and capital sector 1 uses a specific factor, land.
} 


$$
\left[\begin{array}{ccc}
\theta_{L 1} & \theta_{N 1} & 0 \\
-\mathrm{B}_{1} & \mathrm{~B}_{1} & \lambda_{K 2} \\
-B_{4} & \mathrm{~B}_{5} & \lambda_{L 2}^{*}
\end{array}\right]\left[\begin{array}{l}
\hat{W} \\
\hat{R} \\
\hat{X}_{2}
\end{array}\right]=\left[\begin{array}{c}
0 \\
\left(B_{2} \hat{S}_{0}-B_{3} \hat{P}_{3}\right) \\
0
\end{array}\right]
$$

Solving (13) by Cramer's rule the following expressions are obtained.

$$
\begin{aligned}
& \hat{W}=-\left(\frac{1}{\Delta}\right)\left[\theta_{N 1} \lambda_{L 2}^{*}\left(B_{2} \hat{S}_{0}-B_{3} \hat{P}_{3}\right)\right] \\
& \hat{R}=\left(\frac{1}{\Delta}\right)\left[\theta_{N 1} \lambda_{L 2}^{*}\left(B_{2} \hat{S}_{0}-B_{3} \hat{P}_{3}\right)\right]
\end{aligned}
$$

where $\Delta=\left[\left\{S_{N L}^{1}\left(\lambda_{L 2}^{*} \lambda_{K 1}-\lambda_{K 2} \lambda_{L 1}\right)-\lambda_{K 2} \lambda_{L 1} S_{L N}^{1}\right\}\left(\theta_{L 1}+\theta_{N 1}\right)-\theta_{N 1} \lambda_{L 2}^{*} \lambda_{K 2}\right]<0$

Note that $|\lambda|=\left(\lambda_{L 2}^{*} \lambda_{K 1}-\lambda_{K 2} \lambda_{L 1}\right)<0$ as sector 2 is capital-intensive vis-à-vis sector 1 with respect to unskilled labour in value terms.

From (14) the following proposition can be easily established.

Proposition 1: While a fall in the price of the high-skill commodity, $P_{3}$, raises the informal wage a drop in emigration of skilled labour, $S_{0}$, lowers the wage.

Solving (13) one gets

$$
\begin{array}{r}
\hat{X}_{2}=\left(\frac{1}{\Delta}\right)\left[\left\{B_{5}\left(\theta_{L 1}+\theta_{N 1}\right)+\theta_{N 1} \lambda_{L 2}^{*}\right\}\left(B_{3} \hat{P}_{3}-B_{2} \hat{S}_{0}\right)\right] \\
(-) \quad(+)
\end{array}
$$

Differentiating equation (4), using (14) - (16) and simplifying the following expression can be obtained.

$$
\begin{gathered}
\hat{X}_{1}=-\left(\frac{S_{N L}^{1} \lambda_{L 2}^{*}}{\Delta}\right)\left[\left(\theta_{L 1}+\theta_{N 1}\right)\left(B_{3} \hat{P}_{3}-B_{2} \hat{S}_{0}\right)\right] \\
(-)
\end{gathered}
$$

Again, differentiations of (6) and (3) yield 
$\hat{X}_{3}=\left(\frac{S_{S K}^{3}}{\theta_{S 3}}\right) \hat{P}_{3}-\left(\frac{S_{0}}{S-S_{0}}\right) \hat{S}_{0}$

From (17) - (19) the following proposition readily follows.

Proposition 2: A fall in the price of the high-skill commodity causes sector 2 to expand and both sectors 1 and 3 to contract. On the contrary, a decline in emigration of skilled labour causes both sectors 1 and 3 to expand but sector 2 to contract.

Intuitions behind propositions 1 and 2 are fairly straightforward. A decline in the price of the high-skill commodity, $P_{3}$, causes sector 3 to contract. The skilled wage falls as its demand plummets. The contracting sector 3 releases capital to the other two sectors by this means producing a Rybczynski type effect in the subsector. Sector 2 expands while sector 1 contracts as the former sector is more capital-intensive than the latter in value sense. On the contrary, owing to a decline in emigration of skilled labour leads to an expansion of sector 3 as the effective endowment of skilled labour of the economy goes up. The expanding sector 3 draws capital from the other two sectors. The capital-intensive sector 2 contracts while the unskilled labourintensive sector 1 expands following a Rybczynski type effect. The retrenched unskilled workers from sector 2 move to sector 1; thereby depressing the informal (rural) wage rate. The return to the sector specific input, $R$, goes up.

Subtraction of (7) from (8) yields

$\left(\frac{W^{*}}{W}-1\right) a_{L 2} X_{2}=L_{U}$

Differentiating (20) we find

$$
\lambda_{L U} \hat{L}_{U}=\left(\frac{W^{*}}{W}-1\right) \lambda_{L 2} \hat{X}_{2}-\frac{W^{*}}{W} \lambda_{L 2} \hat{W}
$$

Use of (14) and (17) and simplification lead to the following expression.

$$
\begin{aligned}
\lambda_{L U} \hat{L}_{U}= & \left(\frac{\lambda_{L 2}}{\Delta}\right)\left(B_{3} \hat{P}_{3}-B_{2} \hat{S}_{0}\right)\left[\left(\frac{W^{*}}{W}-1\right) B_{5} \theta_{L 1}+\theta_{N 1}\left\{\left(\frac{W^{*}}{W}-1\right) \lambda_{L 1}\left(S_{L N}^{1}+S_{N L}^{1}\right)-\lambda_{L 2}^{*}\right\}\right] \\
(-) & (+) \quad(+) \quad(+) \quad(+)
\end{aligned}
$$


Using (20) from (21) the following results can be easily obtained.

$$
\left(\frac{\hat{L}_{U}}{\hat{P}_{3}}\right)<0 \text { if } A \geq 0
$$

$$
\left(\frac{\hat{L}_{U}}{\hat{S}_{0}}\right)>0 \text { if } A \geq 0
$$

where $\left.A=\left[\lambda_{L U} \lambda_{L 1}\left(S_{L N}^{1}+S_{N L}^{1}\right)-\frac{W^{*}}{W}\left(\lambda_{L 2}\right)^{2}\right] \quad\right)$

These results can be stated in terms of the following proposition.

Proposition 3: A drop in the price of the high-skill product worsens the unemployment problem if $A \geq 0$. On the contrary, the urban unemployment problem of unskilled labour improves following a fall in emigration of skilled labour if $A \geq 0$.

Proposition 3 can be intuitively explained in the following fashion. A fall in the price of the highskill commodity, $P_{3}$, raises both the rural sector wage and the output of sector 2 i.e. $X_{2}$. This leads to an increase in the number of jobs available in the urban sector. The expected urban wage for a prospective rural migrant, $\left[W * /\left\{1+\left(L_{U} / a_{L 2} X_{2}\right)\right\}\right]$, rises as the probability of getting a job in this sector rises for every unskilled worker. This is the centrifugal force that drives the rural workers to move towards the urban sector. This paves the way for fresh migration from the rural to the urban sector. On the other hand, as the rural sector wage increases the centripetal force prevents rural workers from migrating into the urban sector. So in this case there are clearly two opposite effects working on determination of the size of the unemployed urban unskilled workforce. The centrifugal force dominates over the centripetal force under the sufficient condition that $A \geq 0$ and the unemployment situation in the urban sector aggravates. Finally, a fall in emigration of skilled labour lowers both the informal (rural) sector wage and the employment level of unskilled labour in the urban sector. So here both the centrifugal and centripetal forces are negative. However, the negative centripetal force outweighs the centrifugal force and the unemployment level of unskilled labour falls under the sufficient condition, $A \geq 0$. 


\subsection{Effects of economic recession on welfare of unskilled labour}

We are now going to analyze the effects of economic recession in the skilled sector on the welfare of the unskilled workers. Unskilled workers in different sectors of the economy earn different wages. The income distribution of the unskilled workers is given as follows.

Wage rate: $\quad W W^{*} \quad 0$

Employment: $\quad L_{1}\left(=a_{L 1} X_{1}\right) \quad L_{2}\left(a_{L 2} X_{2}\right) \quad L_{U}$

As the wage incomes of the different groups of unskilled workers differ, there is a positive Ginicoefficient, $G$, of the income distribution of the unskilled workers.

The welfare measure of Sen (1974), defined as the per-capita income multiplied by one minus the Gini-coefficient of the income distribution, is an appropriate measure of welfare of the unskilled workers. Let $V$ be the social welfare measure of Sen (1974) which is given as follows.

$V=Y(1-G)$

where $Y$ is the average wage income of all the unskilled workers. We note that

$Y=W * a_{L 2} X_{2}+W a_{L 1} X_{1}$

Using (7) and (8) from (24) we find that

$Y=W$

Also $Y G=L_{2} L_{1}\left(W^{*}-W\right)+L_{2} L_{U} W^{*}+L_{1} L_{U} W$

Using (23), (25) and (26) and simplifying we can write ${ }^{2}$

$V=W\left[1-L_{U}\left(1+L_{1}\right)\right]$

Differentiating (27) the following proposition can be proved. ${ }^{3}$

Proposition 3: A drop in emigration of skilled labour lowers welfare of unskilled workers if $\theta_{N 1} \geq\left(S_{L N}^{1}+S_{N L}^{1}\right)$. On the contrary, a decrease in the price of the high-skill commodity may improve welfare of unskilled workers if $\theta_{N 1} \frac{W^{*}}{W}\left(L_{2}\right)^{2} \geq\left(S_{L N}^{1}+S_{N L}^{1}\right)$.

\footnotetext{
2 See appendix I.

${ }^{3}$ See appendix III.
} 
It should be noted that the conditions as stated in proposition 3 are only sufficient ones. The results may hold under alternative conditions as well.

\section{Policy implications of results and concluding remarks}

The current economic recession though originated in developed countries, has started to bite the economies of even many developing countries. India is no exception. Rates of economic growth have fallen sharply and massive job losses and increasing poverty are all shaking the economic foundation of these countries. The developed countries have desperately fallen back upon monetary and fiscal measures for getting out of the crises. Besides, in a bid to protect domestic jobs they have laid off numerous migrant workers and restricted the entry of new skilled migrants into the country. This protectionist policy on the part of developed nations adds to the dismay of the developing countries. In this backdrop this paper has examined the implications of economic recession in the high-skill sector on the wellbeing of the informal sector workers in terms of a three-sector Harris-Todaro model with an urban high-skill sector. A fall in the world price of the high-skill commodity and a drop in emigration of skilled labour are found to produce dissimilar effects on the unskilled workforce. Both the average wage and urban unemployment of unskilled labour increase following a reduction in the price of the high-skill product while a drop in emigration of skilled labour produces exactly the opposite effects on the informal wage and unemployment. Given these effects in order to protect the interest of the weaker section of the workforce the country should protect its unskilled labour-intensive sectors (sector 1) and resort to a price subsidy policy which would not only increase the informal (rural) sector wage but also lower the urban unemployment of unskilled labour. The policy, therefore, is expected to result in an unequivocal improvement in the wellbeing of the poorer group of the working population. 


\section{References:}

Agenor, P.R. (1996): 'The labour market and economic adjustment', IMF Staff Papers 32, 261 355.

Harris, J.R. and Todaro, M. P. (1970): 'Migration, unemployment and development: A twosector analysis', American Economic Review 60, 126-42.

ILO (2009): 'The financial and economic crisis: a decent work response', International Labour Office, Geneva.

Sen, A. K. (1974): ' Informal bases of alternative welfare approaches: aggregation and income distribution', Journal of Public Economics 4, 387-403. 


\section{Appendix I: Derivation of $V$ function}

Using (25), (26) equation (23) may be rewritten as follows.

$$
\begin{aligned}
V & =W-L_{2} L_{1}\left(W^{*}-W\right)-L_{2} L_{U} W^{*}-L_{1} L_{U} W \\
& =W-L_{2} W^{*}\left(L_{1}+L_{U}\right)+W L_{1}\left(L_{2}-L_{U}\right) \\
& =W-L_{2} W^{*}\left(L_{1}+L_{U}\right)+W L_{1}\left(L_{2}-L_{U}\right) \\
V & =W-L_{2} W *\left(1-L_{2}\right)+W L_{1}\left(L_{2}-L_{U}\right) \quad \text { (obtained after using (7)) }
\end{aligned}
$$

Using (8.1) and simplifying we get

$V=W\left[1-L_{U}\left(1+L_{1}\right)\right]$

\section{Appendix II: Derivations of expression for $\hat{L}_{1}$ and $\hat{L}_{2}$}

Employment in sector 1, denoted $L_{1}$ is given `

$L_{1}=a_{L 1} X_{1}=\left(\frac{a_{L 1} N}{a_{N 1}}\right)$

Differentiating (A.1) one obtains

$\hat{L}_{1}=-\left(S_{L N}^{1}+S_{N L}^{1}\right)(\hat{W}-\hat{R})$

(Note that $\left(S_{L L}^{1}+S_{L N}^{1}\right)=0$ )

Using (14) and (15) equation (A.2) may be rewritten as follows.

$\hat{L}_{1}=\frac{\left(\theta_{N 1}+\theta_{L 1}\right)\left(S_{L N}^{1}+S_{N L}^{1}\right) \lambda_{L 2}^{*}}{\Delta}\left(B_{2} \hat{S}_{0}-B_{3} \hat{P}_{3}\right)$

So a decrease in the price of the high-skill commodity $\left(P_{3}\right)$ lowers the rural sector employment of unskilled labour, $L_{1}$, while a fall in emigration of skilled labour $\left(S_{0}\right)$ raises $L_{1}$.

Employment in sector 2, denoted $L_{2}$, is given by 
$L_{2}=a_{L 2} X_{2}$

Differentiation of (A.4) yields

$\hat{L}_{2}=\hat{X}_{2}$

(Note that $\hat{a}_{L 2}=0$ as $\hat{R}=0$ )

From (A.2) and (17) it follows that

$\hat{L}_{2}=\left(\frac{1}{\Delta}\right)\left[\left\{B_{5}\left(\theta_{L 1}+\theta_{N 1}\right)+\theta_{N 1} \lambda_{L 2}^{*}\right\}\left(B_{3} \hat{P}_{3}-B_{2} \hat{S}_{0}\right)\right]$

$(-)$

$(+)$

Therefore, a decrease in the price of the high-skill commodity $\left(P_{3}\right)$ raises the urban employment of unskilled labour, $L_{2}$, while a fall in emigration of skilled labour $\left(S_{0}\right)$ lowers $L_{2}$.

\section{Appendix III: Effects of changes in $P_{3}$ and $S_{0}$ on $V$}

$$
\left(\frac{d V}{d S_{0}}\right)=\left(\frac{d W}{d S_{0}}\right)\left[1-L_{U}\left(1+L_{1}\right)\right]-W\left(1+L_{1}\right)\left(\frac{d L_{U}}{d S_{0}}\right)-W L_{U}\left(\frac{d L_{1}}{d S_{0}}\right)
$$

$$
(+) \quad(+) \quad(-)
$$

From (A.7) it follows that

$$
\left(\frac{d V}{d S_{0}}\right)>0 \text { if }\left(1+L_{1}\right)\left(\frac{d L_{U}}{d S_{0}}\right)+L_{U}\left(\frac{d L_{1}}{d S_{0}}\right) \leq 0
$$

Using (21) and (A.3) from (A.8) it can be shown that

$$
\left(\frac{d V}{d S_{0}}\right)>0 \text { if } \theta_{N 1} \geq\left(S_{L N}^{1}+S_{N L}^{1}\right)
$$

Differentiating (27) with respect to $S_{0}$ we get

$$
\left(\frac{d V}{d P_{3}}\right)=\left(\frac{d W}{d P_{3}}\right)\left[1-L_{U}\left(1+L_{1}\right)\right]-W\left(1+L_{1}\right)\left(\frac{d L_{U}}{d P_{3}}\right)-W L_{U}\left(\frac{d L_{1}}{d P_{3}}\right)
$$

$$
(-) \quad(+)
$$

From (A.10) it follows that 
$\left(\frac{d V}{d P_{3}}\right)>0$ if $\left(1+L_{1}\right)\left(\frac{d L_{U}}{d P_{3}}\right)+L_{U}\left(\frac{d L_{1}}{d P_{3}}\right) \geq 0$

Using (21) and (A.3) from (A.11) one finds that

$\left(\frac{d V}{d P_{3}}\right)>0$ if $\theta_{N 1} \frac{W^{*}}{W}\left(L_{2}\right)^{2} \geq\left(S_{L N}^{1}+S_{N L}^{1}\right)$ 